\title{
Los medios toman partido
}

\author{
Miguel ngel Vázquez Bermúdez \\ mavazquezb@telefonica.net
}

\begin{abstract}
Resumen
El profuso debate académico sobre la objetividad informativa carece hoy de sentido según se desprende de la observación de la forma de actuar de los medios de comunicación. El proceso de producción de la noticia es interpretativo y está cruzado de una secuencia de decisiones de exclusión e inclusión de carácter subjetivo, pero sobre todo porque los mass media se apartan del ideal de la neutralidad y de información veraz a través del periodismo de declaraciones. De un lado, cuando el periodista desde una posición pasiva se limita a reproducir sin más comprobación las palabras de las fuentes $y$, de otro, cuando priman los intereses ideológicos de la empresa en la confección del temario. Con esta última actitud los medios dejan de cumplir su función social de mediación, toman partido e intervienen como un actor más en el debate político.
\end{abstract}

\begin{abstract}
The profuse academic discuss on the informative objectivity makes no sense today according to is come off the observation of the form to act of mass media. The process of production of the news is interpretative and is crossed of a sequence of decisions of exclusion and inclusion of subjective character, but mainly because mass media separates from the ideal of the neutrality and truthful information through the journalism of declarations. Of a side, when the reporter from a passive position limits itself to reproduce without more verification the words of the sources and, of another one, when they prioritize the ideological interests of the company in the preparation of the agenda. With this last attitude the media let fulfill their social function of mediation, take party and play as an actor more in the political contest.
\end{abstract}

Palabras clave: Objetividad, periodismo de declaraciones, fuentes, mediación, distorsión ideológica.

Key words: Objectivity, journalism of declarations, sources, mediation, ideological distortion.

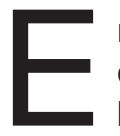

n cualquier manual de Periodística se recoge la objetividad como principio que debe guiar la actuación de los profesionales de la información. La vasta bibliografía sobre este concepto central en el estudio de la comunicación de masas coincide en definir la objetividad como un valor límite o un desideratum, una aspiración difícil (si no imposible) de alcanzar, aunque exigible desde el punto de vista deontológico. Es éste un "concepto ideal-típico", virtual, pero que se manifiesta como "una tensión permanente y reconocible hacia la verdad" (Bechelloni, 1978:177) en el desarrollo de la labor periodística. 
El concepto de objetividad ha sido objeto de un prolijo debate teórico entre sus defensores y detractores. En el extremo de la utopía del profesionalismo se identifica objetividad como ausencia de mediación. Se salvaguarda el carácter apolítico del periodista o, al menos, una demostrada contención de su subjetividad en el ejercicio de su profesión, una estricta observancia moral de la objetividad informativa, de exigencia de probidad profesional frente a la información de actualidad que se transmite (Janowitz, 1975; Desantes, 1976; Martínez Albertos, 1978). Desde esta posición teórica se asocia profesionalidad e información objetiva. Se concibe el mensaje informativo como no intencional y se dictamina que la actuación del periodista se rige por el ánimo de objetividad, por una disposición psicológica de actuar con integridad, de transmitir unos datos que reproduzcan con fidelidad lo acontecido y den una respuesta satisfactoria a los intereses de la audiencia. Esta lectura de la no intencionalidad se enmarca en el viejo aforismo que considera que los hechos son sagrados y los comentarios son libres.

En el polo opuesto, los defensores del periodismo de denuncia, del modelo del advocate, enfatizan la necesidad del papel de vigilancia del poder por parte de la prensa y de la implicación del periodista en los asuntos de los que informa; el profesional se compromete, no permanece al margen de situaciones que también le afectan como ciudadano.

Otras corrientes de pensamiento encuentran la objetividad como "un obstáculo para la comunicación" (Rodrigo Alsina, 1989) al cortar al periodista la posibilidad de ser intérprete de los acontecimientos. Así, el periodismo objetivo sería un mecanismo que permite a los gobernantes y las elites de la sociedad transmitir a través de los medios, y sin ningún tipo de filtro, su interpretación de la realidad (Eco, 1979; Chomsky y Herman, 1990; Ramonet, 1998). Este tipo de actitud favorece el rol de la fuente y prima el pseudo-acontecimiento como constructor de la realidad social: el periodista no informa de un hecho, sino que traslada la noticia a su audiencia sin más comprobación que la supuesta legitimación social del informante. Se hace un mero periodismo de declaraciones que, aunque apuntala un cierto idealismo objetivo, tiene más de desinformación que de información al situar al periodista como un intermediario mecánico y despojado de su papel de intérprete.

Frente al controvertido concepto de objetividad, al que se puede anhelar legítimamente, resulta exigible desde cualquier punto de vista teórico la adopción de una postura neutral o de no implicación personal, la ausencia de partidismo, la búsqueda de la exactitud y de otros criterios que sublimen la veracidad, como la pertinencia y la globalidad de la información, y la inexistencia de motivos de servidumbre a un tercero. Se impone la necesaria independencia del medio y del periodista en su quehacer diario. Sólo desde esta autonomía en el ejercicio profesional se puede prestar un servicio fidedigno a la sociedad. Ésa es la línea que se refuerza en los libros de estilos de los distintos medios de comunicación. Por ejemplo, en el manual de Canal Sur Televisión (2004) se recomienda ajustar el trabajo de su redacción a la imparcialidad, entendida como información equilibrada, 
libre de prejuicio y respetuosa con la verdad, y la independencia respecto al poder, empresas o grupos de presión.

La labor hermenéutica que ha de cumplir el periodista se encuentra lastrada por dos derivas que desembocan en periodismo de declaraciones y que reducen la función social que tienen asignada tanto profesionales como medios de comunicación. Estos desvíos se concretan en una doble vertiente:

a) Cuando la elaboración de la noticia se limita a la reproducción de las manifestaciones de las fuentes, sin interpretación ni la comprobación y la contextualización preceptivas de las mismas. En esta variante del periodismo informativo lo dicho desplaza al hecho, la fuente se salta la mediación y sus opiniones llegan sin filtro a la audiencia al adoptar tanto el redactor como el medio una actitud pasiva y vicaria respecto a los actores sociales, fundamentalmente institucionales.

b) Cuando la información se ciñe a decisiones de carácter ideológico. En este caso, los intereses y la línea editorial de la empresa desplazan otros postulados de carácter profesional y deontológico. En la producción de la noticia priman criterios políticos y el medio ( $y$, por omisión, su redacción) actúa con intencionalidad.

Estos dos tipos de conductas (formas poco edificantes de entender el periodismo) conviven en el sistema informativo español y saltan a la vista en un simple repaso del quehacer de los mass media.

\section{REALIDAD VERSUS TEORÍA}

El mito de la objetividad se desvanece en virtud de los elementos endógenos y exógenos que condicionan la fabricación de la noticia. En primer lugar, los medios construyen una realidad que transmiten a sus audiencias como consecuencia de una serie de decisiones en cada una de las fases de la producción de la actualidad. Se opta por unos escenarios orillando otros, se apuesta por unos acontecimientos en detrimento de otros, unas fuentes reciben más atención que otras, unos detalles preponderan sobre otros, un enfoque desplaza a otros posibles, se escoge unas palabras en lugar de otras. En fin, la fabricación de la información conlleva una serie de determinaciones subjetivas que moldean el producto informativo desde la visión de los medios de comunicación.

La noticia así construida no es una reproducción literal de la realidad, sino el resultado de la interpretación subjetiva de ésta. Los medios de comunicación no son ni marco ni espejo de la realidad. En la recepción y elaboración de la información hay un proceso interpretativo (Van Dijk, 1990). Esta idea del periodista como hermeneuta de la realidad ya está presente en la obra de Ortega y Gasset (1969), al referirse en El espectador a que ésta "no puede ser mirada sino desde el punto de vista que cada cual ocupa, fatalmente, en el universo". El lenguaje es siempre subjetivo porque proviene de un sujeto que articula un mensaje de acuerdo 
con su propia concepción del mundo, desde su particular percepción del entorno social o cultural, con la inevitable influencia de determinadas creencias e ideologías. Entre los paladines de la objetividad como valor sobre el que ha de pivotar el trabajo del periodista, la subjetividad no ha de ir más allá de la manipulación lingüística imprescindible de la realidad para conseguir elaborar un mensaje adecuado, comprensible y no intencional.

Con todo, esta visión utópica de la profesión periodística no contempla otros aditamentos que ejercen una influencia directa sobre la producción de la noticia y, por extensión, de la construcción de la realidad social. Hay estudios del comportamiento de los medios que consagran la subjetividad que recorre todo el proceso de producción de la noticia. Un trabajo sobre los espacios informativos de cadenas de televisión de Reino Unido, Canadá y Estados Unidos (Kline, 1992), extrapolable en cierta medida a prensa y radio, constata que el trabajo periodístico está cruzado por cuatro principales tipos de sesgos, aunque la tradición periodística de cada país delimita su propia versión de la objetividad (o imparcialidad), que varía según los distintos modelos culturales.

Estas desviaciones se resumen en sesgo de contenido, de las fuentes, temático y retórico. El sesgo de contenido refleja la línea editorial del medio a través de la selección y jerarquización de los acontecimientos, así como del tipo de cobertura que depara en función de su posición empresarial. En cuanto a las fuentes, se alude a la elección de autoridades y especialistas que interpretan el acontecimiento para implementar la orientación del medio. El sesgo temático está relacionado con el modelo cultural al que pertenece el periodista y este "pattern familiar" lo lleva a optar por unos temas y descartar otros que no casan con los valores sociales y culturales de cada país. Por último, el sesgo retórico se refiere a los distintos aspectos que en la redacción del relato informativo quiebran la supuesta objetividad: la utilización de elementos opinativos, la atribución de causas, el tono apreciativo, la coordinación de imagen-comentario o la calidad de la filmación.

Esta propuesta sugiere algunos de los motivos que empujan a los mass media a apartarse de la imparcialidad que se reclama desde atalayas teóricas. El medio confecciona su producto informativo en función de sus propias necesidades, carencias e inclinaciones políticas. La organización de la redacción, las rutinas productivas, las fuentes, la ideología del medio y los intereses de éste como empresa y la dependencia económica repercuten sobre la confección del temario.

La noticia queda condicionada, en primer lugar, por su estructura de funcionamiento, dispuesta en una disposición piramidal fuertemente jerarquizada que repercute en el producto final, añadiendo una mayor subjetividad al ejercicio profesional. Los periodistas adaptan sus puntos de vista y forma de actuar a las exigencias de su empresa. Conocedores de la línea editorial o del modelo informativo del medio adecuan los enfoques de sus relatos a la línea discursiva del medio. Desde el pionero estudio de Breed (1955) hasta nuestros días, diferentes investigaciones (Sigelman, 1973; Epstein, 1973; Rodrigo Alsina, 1989) han constatado los efectos de la redacción en la actuación de los periodistas. El profesional se socializa como 
mecanismo de autodefensa y promoción profesional, que se traduce en seguir la orientación ideológica o la política marcada por la propiedad del medio. El proceso socializador busca preferentemente evitar las tensiones en la redacción y, para ello, "lo que hace el redactor es aprender a anticipar lo que se espera de él, a interiorizar los derechos y obligaciones de su status, a conseguir premios y a evitar castigos" (Gomis, 1991). Así, la organización influye directamente en la interpretación de la realidad.

La dinámica de trabajo de los mass media distorsiona la percepción de la realidad por parte del público. La escasez de recursos y la exigencia de un tiempo de producción reducido cincelan unas rutinas en las que se prima el pseudoacontecimiento, organizado por autoridades e instituciones públicas y privadas, porque propicia un flujo constante de ítems noticiables. La accesibilidad de la información y la adaptación de ésta al periodo de difusión se erigen en valores/ noticias fundamentales para la confección del temario. Ya Lippmann en 1992 reparó en la tendencia de los reporteros de acudir a lugares específicos donde se acopia con facilidad información. Aunque estos apelan al interés general a la hora de incluir una noticia, la realidad demuestra que los factores que mueven a la empresa periodística son el tiempo, la distancia, rentabilidad económica, esto es, predominan criterios de racionalización del proceso productivo, que conducen a una homogenización de la noticia. Así, el método de producción delimita el concepto de noticia.

Los mass media ahorran en recursos humanos y técnicos, mientras que las instituciones salen beneficiadas por este sistema que "le permite colar su información sin filtros" (De Fontcuberta, 1998). Esta simbiosis entre ambos actores afecta a los criterios de noticiabilidad y da alas a las fuentes para organizar estrategias de ocupación de tiempo y espacio mediáticos, con lo que se pone a disposición de la audiencia un producto informativo excesivamente condicionado por los proveedores institucionales. Los medios de comunicación sólo cumplen parcialmente su función social de mediación por la dependencia de las fuentes y unas rutinas productivas que priman la cantidad sobre la calidad y se pliegan a las agendas marcadas por terceros.

Se fomenta así el periodismo de declaraciones, una práctica extendida en la profesión que favorece la difusión de las opiniones de las fuentes y que transmite la impresión de que el medio favorece a personajes públicos a través de entrevistas breves o declaraciones en comparecencias públicas a las que el protagonista sólo tiene que responder, sin más objeciones por parte del periodista, la frase efectista que se le conviene. Apenas si existen posibilidades para dar un giro a esta deriva, donde el protagonismo lo acapara "la noticia caliente sin explicar -no hay tiempo, no hay espacio-, el espectáculo de los hechos, el cruce de declaraciones que la representación política genera, la propaganda y la publicidad" (Casals, 1999). Se traslada la noticia a su audiencia sin más comprobación que la supuesta legitimación social del informante, por lo tanto, "las noticias se hacen inseguras, quien dispone del poder se salta la mediación y habla directamente a la gente" (Colombo, 1997). 
El poder financiero de la empresa rebaja teóricamente la necesidad de la información de agenda: cuantos más recursos profesionales, técnicos y económicos tienen los medios, más capaces resultan de introducir lo imprevisto y cuanto más precarios sean, mayor será el peso de la programación y la información de segunda mano. Lógicamente, el medio con menos potencial económico cuenta con menos resortes humanos y materiales, una situación que lo fuerza a seguir la agenda que le organizan las fuentes y a depender más de las agencias de noticias para confeccionar el producto informativo final.

El afán por ofrecer una visión idealizada de la actividad periodística, relacionada con conceptos tales como el olfato informativo, la neutralidad, la independencia o la objetividad, queda en entredicho y la realidad es que la producción de la noticia es un proceso rutinizado en el que intervienen otros factores además del interés general o el interés de las respectivas audiencias.

\section{EL SESGO POLÍTICO}

El periodismo de declaraciones no sólo se manifiesta en esta dirección, en la que los medios de comunicación adoptan un rol pasivo, otorgando toda la iniciativa a unas fuentes ávidas por hacer llegar a la audiencia un mensaje interesado. La otra cara de la misma moneda de este periodismo de remitidos se produce cuando las inclusiones, las exclusiones y las jerarquizaciones de los acontecimientos y las declaraciones de los actores sociales tienen una motivación de corte político, asumiendo así un papel activo acorde a los intereses o su línea editorial de la empresa informativa.

Cada día resulta más palmario el hecho de que algunos medios de comunicación actúan como un agente activo más en el debate político que tiene lugar en el espacio público español. Las tradicionales funciones sociales atribuidas a los mass media de informar, formar y entretener cada vez ceden más espacio a fines más prosaicos como ganar dinero y ejercer influencia.

La necesidad de la empresa informativa por cuadrar su cuenta de resultados y, si es posible, obtener beneficios supone una respuesta lógica a la dinámica de mercado de las sociedades avanzadas. Se produce una paulatina priorización de los aspectos comerciales, se antepone el interés crematístico, la supervivencia a través de la captación de audiencia a cualquier precio, lo que supone una pérdida de responsabilidad social (De Fontcuberta, 1998).

Más preocupante si cabe que la banalización y la espectacularización del acontecimiento y su información resulta el abandono del rol de mediador entre la sociedad y poderes públicos para convertirse en protagonista activo del debate público. El papel del periodista como intérprete, como fedatario público de la actualidad, cede terreno hacia una forma de entender la noticia marcada por el posicionamiento ideológico del medio. El profesor Díaz Nosty (1996) ha puesto de manifiesto "la progresiva aproximación de los entornos del emisor a la condición de 
fuente, protagonista o inductor directo de lo que se presenta como actualidad". En esta forma concebir la interpretación de la realidad prima el sesgo político ante cualquier otra consideración. Esta deriva pone en solfa el deber de mediación social que tiene que desempeñar el sistema informativo en una sociedad democrática. Si se actúa como juez y parte, se hace una renuncia a los valores deontológicos que perfilan la actividad periodística.

Esta desorientación del quehacer periodístico recolecta críticas incluso desde el seno de la propia profesión. Un relevante periodista como Luis del Olmo hacía una radiografía preocupante de la situación al admitir que "la radio en España lleva el lastre del alineamiento político". En esa toma de posesión, el medio delinea una concepción de lo que acontece en la que "premia a los suyos y castiga a los otros" (Casals, 1999).

\section{PERIODISMO DE TRINCHERA EN ESPAÑA}

Este fenómeno de la ideologización de la información y el consecuente frentismo mediático como extensión de la dialéctica política no es nuevo en España. El periodista Luis María Anson ha reconocido que se orquestó una acción concertada o una conspiración política entre el Partido Popular, varios medios de comunicación y algunos empresarios para derribar al Gobierno socialista en las elecciones generales de 1996. El objetivo era derrotar a Felipe González a toda costa y así lo explicaba a la revista Tiempo (número del 16 de febrero de 1998) el hoy catedrático de la Real Academia Española de la Lengua y ex director de $A B C$ y La Razón: "Había que terminar con Felipe González, ésa era la cuestión. Al subir el listón de la crítica se llegó a tal extremo que en muchos momentos se rozó la estabilidad del propio Estado. Eso es verdad. Tenía razón González cuando denunció ese peligro..., pero era la única forma de sacarlo de ahí". Para conseguir este fin, algunos medios ( $E I$ Mundo, $A B C$ y la Cadena COPE fueron los tres principales arietes) participaron activamente en esa operación: "Los medios reaccionaron atizando algunas situaciones. Ése fue el caso de los conflictos y el papel de la justicia. Al atizar el fuego en ese sector se favorecía la erosión de González... Así que se hizo. Fue una operación de acoso y derribo. Algunos lo hicimos desde el convencimiento honesto de que era un servicio al sistema democrático. (...) Desde una labor crítica normal no se conseguía desalojar a González del poder”.

Esta implicación del periodismo en la arena política marca un antes y un después en la trayectoria del periodismo español desde la recuperación de la democracia. De la mera observación de los medios de comunicación españoles se detecta la existencia periodistas militantes que, "desde la plataforma de alguna ideología o creencia concreta, se afanan en la crítica o denuncia de todo cuanto no encaje o se desvíe de sus más o menos delimitados marcos referenciales" (Rodríguez, 1994:40).

Esta denuncia tiene hoy plena vigencia y se puede verificar, por ejemplo, en el tratamiento que está recibiendo por parte de algunos medios y algunos profesiona- 
les las especulaciones sobre el inicio de un proceso de negociación entre el Gobierno español y la banda terrorista ETA. Como muestra un botón, aquellos que en 1998 acogían de buen grado el intento del Ejecutivo de José María Aznar de buscar el final de violencia en una reunión con la dirección de organización etarra en Suiza, hoy censuran con dureza la posibilidad esbozada por el presidente actual, José Luis Rodríguez Zapatero, de desbrozar el camino hacia la paz. Hace casi ocho años se podía leer editoriales y columnas del siguiente tono: "Otro valiente paso de Aznar hacia la paz" (Editorial de El Mundo, 4 de noviembre de 1998); "Horizonte de esperanza" (Editorial de ABC, 4 de noviembre de 1998); "Con tacto" (Federico Jiménez Losantos, El Mundo, 4 de noviembre de 1980) o "¿Negociar con ETA? La respuesta adecuada" (Justino Sinova, El Mundo, 8 de noviembre de 1998). Estos mismos medios y periodistas hablan hoy de claudicación y rendición a la banda terrorista, una visión de esta iniciativa casualmente coincidente con las del Partido Popular. ¿Fortuita concurrencia o estrategia compartida?

Este escoramiento político se pone de manifiesto no sólo en las páginas de opinión, algunas investigaciones lo detectan también en las de información. En su artículo Elecciones 2000: Carrera de caballos y partidismo mediático, Sádaba Gamarra y Vara Miguel (2003) demuestran que en el seguimiento de los comicios generales de ese año el PP ha gozado de mayor visibilidad en El Mundo y el PSOE, en El País. Y concluyen que "los periodistas no han sabido responder a su función pública puesto que han sido una parte activa en la contienda partidista. La inclinación demostrada [...] ha dado lugar a lo que podríamos llamar un periodismo militante, especialmente significativo a la hora de juzgar las virtudes del bando en que se atrinchera".

En España en portada (Martínez Fresneda et al., 2004), una investigación que analiza de las primeras páginas de El País, $A B C$, El Mundo y La Razón entre el 28 de febrero y el 12 de junio de 2004, se confirma que la línea editorial se pone de manifiesto en el tratamiento informativo, tanto en la forma como en el fondo, de los distintos acontecimientos destacados en las mismas. Es más, se constata que los diarios ofrecen en su página más destacada y de referencia los principios básicos de la línea editorial y, sobre todo, se explicita su posicionamiento ideológico con el fin de orientar a la opinión pública.

Otra certificación de la ideologización de la conducta de la prensa española queda recogida en mi tesis doctoral, Periodismo de declaraciones: el pseudoacontecimiento como base de la producción de la noticia. Los casos de El País, El Mundo y $A B C$ (Vázquez Bermúdez, 2005). El trabajo de campo, análisis de contenido realizado sobre un corpus de 1.026 textos de los tres periódicos correspondientes a sus ediciones de la última semana de mayo de 2004, certifica también que la línea editorial de cada medio influye, en algunos casos decisivamente, en la selección de las declaraciones de los actores sociales y en la jerarquización de los relatos. Esquemáticamente, se infiere de la lectura de estos diarios que El Mundo y $A B C$ inclinan la información hacia posiciones conservadoras y que El País se escora a las posiciones socialistas. 
Esta panorámica general encierra una distinta gradación en la actuación sesgada de cada medio impreso y en el cumplimiento del deber de responsabilidad social. El Mundo es, sin duda, el que manifiesta de forma más explícita en su temario el ascendiente ideológico en el proceso de producción de la noticia; se acredita nítidamente una selección favorable a las posiciones del Partido Popular (información más abundante, mejor valorada en extensión, ubicación y apoyo gráfico y tipográfico, pero sobre todo se favorece la difusión de la visión de esta formación política con la inclusión de sus declaraciones en bruto y respetando su literalidad) y crítica con las del PSOE tanto en términos cuantitativos como cualitativos.

En $A B C$, por el contrario, se confirma una repercusión de su posición editorial sobre la información política, pero de forma menos elocuente que en El Mundo. La línea ideológica del rotativo de Vocento se manifiesta con claridad en su alineamiento sin fisuras con la Casa Real española (su carácter monárquico se traduce en un tratamiento deferente a las actividades de los representantes de la Corona) y en la oposición a aquellos asuntos que no coinciden con la moral cristiana.

El País es de los tres el periódico más equilibrado en el tratamiento de la información, aunque no está exento de deslizamientos políticos motivados por la línea editorial. Se testa una más y mejor cobertura sobre las actividades del Gobierno de la nación que sobre la oposición, es decir, del PSOE que del PP. EI rotativo del Grupo Prisa salda cuentas pendientes con el anterior Ejecutivo español, presidido por Aznar, en temas como los atentados del 11 de marzo de 2004 en Madrid o la posguerra de Irak.

De estos ejemplos así como de la observación diaria de la actualidad informativa de los distintos medios que operan en España se definen nítidamente dos bandos mediáticos. En la esfera privada, medios como El Mundo, ABC, La Razón, la Cadena COPE, Onda Cero o Antena 3 privilegian la visión del Partido Popular en detrimento de otras opciones políticas. Por el contrario, en otros como El País, la Cadena Ser o El Periódico de Catalunya se registra una inclinación hacia el PSOE. Estos dos bloques no sólo se limitan a la toma de partido, sino que entre ellos existe una agria dialéctica de combate. En los medios públicos de comunicación se está modificando la tendencia histórica a plegarse al poder ejecutivo de cada ámbito político, un proceso que además se va dinamizando por una serie de iniciativas legislativas, ya en proceso parlamentario, para garantizar la desgubernamentalización de la información en la radio y la televisión públicas.

\section{CONCLUSIÓN}

El medio, al menos en la teoría, ha de mediar entre la sociedad y los poderes establecidos como instrumento socialmente legitimado para la transmisión del saber cotidiano al gran público. Esta mediación supone una valoración del hecho a través del proceso rutinizado de captación, selección y jerarquización de los acontecimientos (Martín Serrano, 1977:54) desde una posición no intencional y de 
neutralidad. Pero, al decantarse por una visión de la realidad desde una óptica politizada, el sistema informativo renuncia a jugar un papel de intermediario entre los diversos estamentos de la sociedad. Ese clima de alineamiento político se percibe con nitidez en el periodismo español y evidencia cómo algunos medios de comunicación han olvidado su papel de intermediación sin sesgo político, sin intencionalidad en su diálogo con la sociedad. Se ha abandonado el papel de vigilante del entorno para participar de una manera activa en la contienda política renunciando a los principios más elementales de la deontología profesional, hasta tal punto que a veces resulta difícil discernir quién marca la estrategia a seguir, el medio o el partido político, lo que induce a sospechar de la existencia de una actuación concertada con intereses compartidos.

\section{BIBLIOGRAFÍA:}

BECHELLONI, Giovanni (1978): “Notizie o interpretazione?", en Problemi dell'informazione, año III, № 4.

BREED, Warren (1955): "Social Control in the New Room: a Functional Analysis", en Social Forces, oㅜ 33, mayo, págs. 326-335.

CANAL SUR TELEVISIÓN Y CANAL 2 ANDALUCíA: Libro de Estilo. RTVA, Sevilla, 2004.

CASALS CARRO, María Jesús (1999): "El arte de la realidad: prospectivas sobre la racionalidad periodística", en Estudios sobre el Mensaje Periodístico, ㄲo 5, Departamento de Periodismo I de la Facultad de Ciencias de la Información de la Universidad Complutense de Madrid.

COLOMBO, Furio (1997): Últimas noticias sobre el periodismo. Manual de periodismo internacional. Anagrama, Barcelona.

CHOMSKY, Noam y HERMAN, Edward S. (1990): Los guardianes de la libertad. Propaganda, desinformación y consenso en los medios de comunicación de masas. Crítica, Barcelona.

DE FONTCUBERTA, Mar (1998): La noticia. Pistas para percibir el mundo. Paidós (Papeles de comunicación 1), Barcelona, 1998 (3ª ed.).

DEL OLMO, Luis (2004): Entrevista publicada en El País, suplemento 'Domingo', el 1 de agosto, págs. 6-7.

DESANTES, José María (1976): La verdad en la información. Diputación Provincial de Valladolid, Valladolid.

DÍAZ NOSTY, Bernardo (1996): "El estado de la comunicación. Informe sobre los medios en España", en DíAZ NOSTY, Bernardo (dir.): Comunicación social $1996 /$ Tendencias. Informes anuales de la Fundesco, Madrid.

ECO, Humberto (1979): "Obbiettivitá dell'informazione, il dibatitto teorico e le transformazioni della società italiana", en AA.VV: Informazione, consenso e dissenso. II Saggiatore, Milán. 
EPSTEIN, Edward J. (2000): News from Nowhere. Television and the News. Ivan R. Dee Publisher, Chicago. (Publicación original en Random House, Nueva York, 1973). GOMIS, Lorenzo (1991): Teoría del periodismo. Cómo se forma el presente. Paidós Comunicación, Barcelona.

JANOWITZ, Morris (1980): "Modelli profesionalli del giornalismo", en AA.VV.: /l giornalismo come professione. II Saggiatore, Milán, 1980, pág. 44 y ss. (Trabajo original: "Professional models in Journalism: the Gatekeeper and the Advocate", en Journalism Quarterly, no 52, primavera, 1975, págs. 618-626).

KLINE, S. (1982): "Les informations téléviseés: structure de leur interpretation de l'actualité“, en Communication et information, vol. 4, nำ3, verano.

MARTíN SERRANO, Manuel (1977): La mediación social. Akal, Madrid.

MARTíNEZ ALBERTOS, José Luis (1978): La noticia y los comunicadores públicos. Pirámide, Madrid.

MARTíNEZ FRESNEDA, Humberto et al. (2004): España en portada. Fragua, Madrid.

ORTEGA Y GASSET, José (1969): El espectador. Salvat, Barcelona.

RAMONET, Ignacio (1998): La tiranía de la comunicación. Temas de debate, Madrid.

RODRIGO ALSINA, Miquel (1989): La construcción de la noticia. Paidós Comunicación, Barcelona.

RODRÍGUEZ, Pepe (1994): Periodismo de investigación. Técnicas y estrategias. Paidós, Barcelona.

SÁDABA GAMARRA, Teresa y VARA MIGUEL, Alfonso (2003): "Elecciones 2000: carrera de caballos y partidismo mediático", en ZER Revista de Estudios de comunicación, ํo 14, mayo.

SIGELMAN, Lee (1973): "Reporting the News: An Organizational Analysis", en American Journal of Sociology, vol. 79, nำ1, Julio, págs. 132-151.

VAN DIJK, Teun A. (1990): La noticia como discurso. Comprensión, estructura y producción de la información. Paidós Comunicación, Barcelona. (Título original: News as discourse, 1980).

VÁZQUEZ BERMúDEZ, Miguel Ángel (2005): Periodismo de declaraciones: el pseudoacontecimiento como base de la producción de la noticia. Los casos de El País, El Mundo y $A B C$. Tesis doctoral, Facultad de Comunicación, Universidad de Sevilla.

(Recibido el 10-03-06, aceptado el 30-05-06) 